\title{
Book review: Community based education in health professions
}

\author{
Shankar PR \\ Chair, Curriculum Committee, Xavier University School of Medicine, Aruba
}

\begin{tabular}{ll}
\hline \multicolumn{2}{l}{ ARTICLE INFO } \\
Received & $: 09 / 03 / 2014$ \\
Accepted & $: 27 / 06 / 2014$ \\
Published & $: 01 / 09 / 2014$
\end{tabular}

\section{KEYWORD}

Case studies,

Community based education, Health professions

\begin{abstract}
Community-based education (CBE) and social accountability of health professions schools are in the spotlight. Different institutions have used a variety of approaches to implement CBE. Learning about the approaches followed, challenges faced, how they were overcome and lessons learned would be of interest to health educators in other institutions. The book provides a selection of case studies or 'stories' from selected schools in Bangladesh, Brazil, Egypt, India, and South Africa. These schools emphasize student education in the community, integrate community medicine throughout the curriculum and preferentially admit financially weak students from rural areas and offer nurses and paramedicals the option to pursue a medical career.
\end{abstract}

(C) Medical Education Department, School of Medical Sciences, Universiti Sains Malaysia. All rights reserved.

CORRESPONDING AUTHOR: Dr. P. Ravi Shankar, Xavier University School of Medicine \#23, Santa Helenastraat, Oranjestad, Aruba, Kingdom of the Netherlands.

E-mail: ravi.dr.shankar@gmail.com

\section{Introduction}

Community-based education (CBE) and social accountability of health professions schools have attracted tremendous attention recently. A number of health education institutions have adopted different approaches and strategies to implement CBE. Learning about the approaches followed and challenges overcome in a specific institution would be of interest to educators in other countries. The Foundation for Advancement of International Medical Education and Research (FAIMER) offers a two year fellowship in health professions education through the institute in Philadelphia, United States and regional institutes in Brazil, China, India and South Africa. FAIMER has the objective of improving world health through education. Recently certain FAIMER fellows have published a book on community based education in the health professions sharing experiences gained in different countries. Experiences from Brazil, Bangladesh, Egypt, India, Pakistan and South Africa are shared in the publication.

The book is authored by Dr Wagdy Talaat from Egypt and Dr Zahra Ladhani from the United States who are fellows and faculty of the FAIMER institute and have done a lot of work on CBE. The authors state that the purpose of the book is to introduce case studies or 'stories' from the developing world (Asia to Latin America) to an international audience. The collection intends to serve as a source of inspiration to others. The stories detail the planning and implementation of CBE, describes what worked and what did not, 
the technical knowhow involved and the lessons learned.

During CBE students learn professional competencies in a community setting and develop a sense of connection with their communities. I had previously been involved in $\mathrm{CBE}$ as the undergraduate medical (MBBS) program coordinator at KIST Medical College, affiliated to the Tribhuvan University. Community Medicine occupies an important place in the curriculum and I was involved with the department of Community Medicine and others in the planning and implementation of residential field and other programs. Recently the Patan Academy of Health Sciences (PAHS), a community-based health school has opened in Nepal with a radically different approach to creating health personnel for rural Nepal. I hope a future edition of the book will contain some description of this unique experiment.

The importance of primary health care in improving the health status of countries was increasingly recognized in the 1970s and CBE got a major boost during this period. The book briefly traces the development of $\mathrm{CBE}$ with description of early pioneers in Australia, Sri Lanka, Thailand, Philippines, Papua New Guinea, Mexico and the Netherlands. Among later models the authors mention the examples of Suez Canal University in Egypt, the University of Gezira, Sudan and Aga Khan University in Pakistan.

Chapter 2 describes the definition and scope of $\mathrm{CBE}$ and its evolution over the years. CBE uses the community as the setting for learning activities, emphasizes university-community partnerships, and focuses on empowering the community to take a more active role in improving their health. The contemporary definition of CBE emphasizes 'facilitation of learning in, with, for, and from the community, rendering relevant, meaningful and mutually agreed upon learning outcomes for health professionals and services to the populations in a community setting.'
Case studies of institutions in selected countries are the main focus of the book. Dr Zafrullah Chowdhury, a well known figure in Bangladesh describes the birth of Gonoshasthaya Kendra which has grown to become the second largest provider of healthcare in Bangladesh after the government. The organization established a medical school in 1998 with the goals of providing free education to meritorious, poor students from rural areas, providing nurses and paramedics with practical work experience the option to pursue a career in medicine and emphasizing community interaction and education. I enjoyed the black and white photos showing students being a part of the daily life of a rural community. All students are well dressed in their white coats in contrast to the informally dressed villagers. I have often pondered whether the white coat acts as a barrier to greater interaction or is a vital part of the professional identity of doctors.

Brazil has recently won accolades for the close relationship between health education and health systems and I was eager to read about the experiences of Ribeirão Preto-University of São Paulo. The school was started in 1952 and the author has succinctly traced the development of $\mathrm{CBE}$ in the institution during the last seventy years. The school emphasizes rural clerkships, school health centres, community medical centres and family medicine units. The brief description of how the school tackled the challenges of student resistance, faculty reluctance, and political issues among others makes for interesting reading. I would have liked a more detailed description of these areas.

In Bangladesh the major challenges were little participation of the community in the education of medical students and the poor health status of the community. The medical school started by Gonoshasthaya Kendra emphasized CBE in rural areas and paramedics played an important role in educating the students. Educational opportunities were provided to rural students and for paramedics interested in further medical training. In Brazil there were regional and income-based disparities in healthcare and the University hospital was the major centre of medical 
education. The system was also highly bureaucratic. Ribeirão Preto-University of São Paulo introduced rural clerkships, training at community medical centres and school health centres. The school had a small group of interested and motivated faculty members and hired members already working in the community. Local communities were involved and there were written agreements between the school and local bodies.

The Faculty of Medicine at Suez Canal University in Egypt uses Primary Health Care Centres (PHCCs) for educating students, conducts community surveys and projects, offers community electives and emphasizes community partnership. The university faced challengers similar to those described previously. The university established a partnership with the Ministry of Health which runs the PHCCs, offered family healthcare programs and involved the community in training medical students with substantial community health benefits. The author very briefly describes student assessment in CBE. As a medical educator I would have liked more information on this important area.

Having interacted closely with health educators from the Christian Medical College, Vellore, during the FAIMER fellowship program at the PSGFAIMER Regional Institute in Coimbatore, India I was interested in knowing more about the Vellore model of CBE. The school in Vellore drew upon its established system of community service and peripheral health centres and hospitals to impart CBE. Aga Khan University in Pakistan is well known for CBE and a detailed description of the CBE program in the institution is provided. The University had selected a squatter settlement in the city of Karachi as the field study area and emphasized community empowerment to improve their health. Faculty development and interprofessional education were also emphasized.

The detailed case study of Stellenbosch University in South Africa highlights how family medicine is integrated throughout the curriculum, long term rural placements are carried out, and interprofessional education achieved, which are strategies now adopted in many other schools. The University established a division of family medicine and primary care and a CBE committee was created. Workshops were conducted and a centre for health professions education started. The Ukwanda rural clinic school was started to provide long term rural exposure to students and interprofessional education emphasized. The authors mention a visionary faculty management, close cooperation with the local service provider, a local champion familiar with the conditions and rural doctors committed to teaching students as key success factors.

The book concludes with a glossary of terms and list of references. Each chapter and case study has a list of references at the end, for many of which URL links are provided. Photographs, diagrams and tables add to the readability of the book. The book is beautifully designed and produced and is a must have for all medical educators considering the increasing emphasis on CBE and social accountability by different governments, communities and accreditation agencies.

\section{About the book:}

Talaat W, Ladhani Z. Community based education in health professions: Global perspectives. WHO Regional Office for the Eastern Mediterranean January 2014. The book can be downloaded for free from http://mesau.mak.ac.ug/sites/default/files/Comm unity $\% 20$ Based $\% 20$ Education $\% 20$ in $\% 20$ Health $\% 20$ Professions $\% 20$ Global\%20Perspectives $\% 20$ Electronic\%20Copy_0.pdf 